\title{
Diel patterns of larval release by five brooding scleractinian corals
}

\author{
Tung-Yung Fan ${ }^{1,2, *}$, Ke-Han Lin ${ }^{1,3}$, Fu-Wen Kuo ${ }^{1}$, Keryea Soong ${ }^{3}$, Li-Lian Liu ${ }^{3}$, \\ Lee-Shing Fang ${ }^{1,2}$
}

\author{
${ }^{1}$ National Museum of Marine Biology and Aquarium, Pingtung, Taiwan 944, ROC \\ ${ }^{2}$ Institute of Marine Biodiversity and Evolution, National Dong Hwa University, Hualien, Taiwan 974, ROC \\ ${ }^{3}$ Institute of Marine Biology, National Sun Yat-Sen University, Kaohsiung, Taiwan 804, ROC
}

\begin{abstract}
Timing of larval release in benthic marine invertebrates plays an important role in determining the reproductive success and extent of larval dispersal. Few studies have been conducted on diel variations in planula release by corals. Five brooding corals Seriatopora hystrix, Stylophora pistillata, Pocillopora damicornis, Euphyllia glabrescens, and Tubastraea aurea in Nanwan Bay, southern Taiwan, were selected to compare diel patterns of planula release. Corals were collected from the field and maintained in outdoor, flow-through systems to quantify the hourly release of planulae. Planulation by $S$. hystrix and $S$. pistillata was highly synchronized with 1 peak of planula release occurring close to sunrise. Planulae of $P$. damicornis and E. glabrescens were released throughout the day, and usually 2 peaks occurred in the early morning and at night. Planulation of the ahermatypic coral $T$. aurea occurred throughout the day without a consistent peak. The diel cycle of planulation for all 3 pocilloporids and E. glabrescens suggests that the light-dark cycle may be the cue that induces planula release. The majority of planulae of these 4 species being released in the dark might be beneficial for minimizing predation effects. The peak planulation occurring close to sunrise might be advantageous for exploiting light cues after sunrise by mature planulae in order to quickly settle, shortening the time they remain in the water column and promoting settlement within the natal reef. Variations in diel patterns of planula release show that variable strategies of reproductive timing exist for brooding species.
\end{abstract}

KEY WORDS: Diel periodicity - Planulation - Coral - Seriatopora hystrix $\cdot$ Stylophora pistillata Pocillopora damicornis · Euphyllia glabrescens $\cdot$ Tubastraea aurea

\section{INTRODUCTION}

Many marine invertebrates share a pelagic larval phase that is critical to their reproductive success, dispersal, and recruitment. Larvae can actively adjust their position in the water column to facilitate settlement or dispersal (Genin et al. 2005, Shanks \& Brink 2005). However, reproductive timing and related environmental conditions can produce large variations in recruitment and dispersal events that influence the abundance, distribution, and connections among populations in different localities (Underwood \& Fairweather 1989).
The timing of reproduction in reef corals has received considerable attention during the last 3 decades (Harrison \& Wallace 1990). Corals can be classified into 2 reproductive groups: brooders and spawners. In brooding species, eggs are fertilized internally, and relatively more-mature planulae are released. After release, brooded planulae have a short precompetency period that ranges from minutes to days, depending on the developmental stage and species (Harrison \& Wallace 1990). In contrast to brooders, broadcast spawners release both eggs and sperm which then fertilize externally. Since brooders release planulae that can competently disperse and settle, the timing of 
planula release is less restrained by fertilization and embryo development, thus possibly reflecting the optimal timing for higher survival and recruitment rates.

Some reproductive studies on brooding corals focused on a single species (Rinkevich \& Loya 1979a,b, Harriott 1983, Szmant-Froelich et al. 1985, Johnson 1992, McGuire 1998). On the other hand, there are only a few comparisons of larval release timing of multiple related species (Stimson 1978, Tanner 1996, Fan et al. 2002, Vermeij et al. 2003). The proximate cues and ultimate selection forces creating and maintaining specific reproductive patterns can be better understood by comparing patterns of reproductive timing in groups of related species. Comparative studies of multiple species are increasing in coral reproduction research (Harrison et al. 1984, Shlesinger \& Loya 1985, Babcock et al. 1986, 1994, Hall \& Hughes 1996, Tanner 1996, Fan et al. 2002, Vermeij et al. 2003).

Brooding corals usually have several reproductive cycles throughout the year that are attuned to lunar periodicity (Harrison \& Wallace 1990, Richmond \& Hunter 1990, Tanner 1996). The seasonality and lunar periodicity of planula release in scleractinian corals have been widely studied, revealing geographical variations (Atoda 1947a,b, 1951, Stimson 1978, Rinkevich \& Loya 1979b, Harriott 1983, Richmond \& Jokiel 1984, Jokiel 1985, Stoddart \& Black 1985, Tanner 1996, Fan et al. 2002). However, only limited research has been conducted on the subject of the diel cycle of planula release, and this was focused mainly on the species Pocillopora damicornis (Holloran \& Witteman 1985, Harrison \& Wallace 1990, Tanner 1996, Isomura \& Nishihira 2001, Tioho et al. 2001). Other studies have reported the timing of planula release but without detailed information on hourly variations in planula production (Rinkevich \& Loya 1979a, Harriott 1983, Szmant-Froelich et al. 1985, Kojis 1986, Morse \& Morse 1991, Johnson 1992, McGuire 1998, Edmunds et al. 2001, Isomura \& Nishihira 2001). The diel timing of larval release can influence the survival of larvae due to avoidance of predator activity, and determine the environmental conditions available to larvae that serve as settling cues e.g. light and tidal height (Olson 1983, Morgan 1995). The diel pattern thus provides important information on the ecological and evolutionary significance of reproductive timing.

In this study, the diel cycle of planulation for 5 brooding coral species Seriatopora hystrix, Stylophora pistillata, Pocillopora damicornis, Euphyllia glabrescens, and Tubastraea aurea was examined. All 5 species are hermaphroditic brooders and encompass a wide range of life history strategies (Harrison \& Wallace 1990, Fan et al. 2002, authors' unpubl. data). They are common in shallow waters on fringing reefs

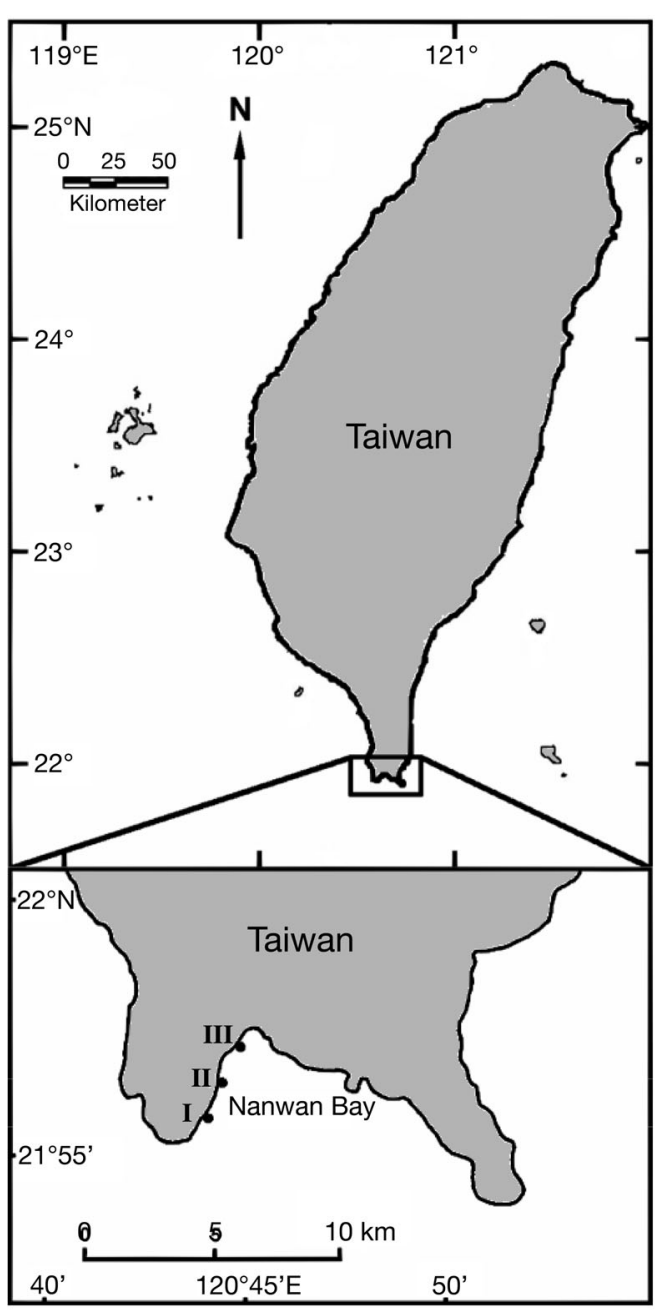

Fig. 1. Collection sites of coral samples in Nanwan Bay, southern Taiwan. I: Leidashyr, II: Hobihu, III: inlet of a power plant

in southern Taiwan (Dai 1989). S. hystrix, S. pistillata, and $P$. damicornis are widely distributed and abundant in shallow water reef environments in the IndoPacific (Veron 2000). They are in the family of Pocilloporidae, have small polyps, form branching colonies and host zooxanthellae. Pocilloporids recruit abundantly and are an important early successional group, typically being among the first to colonize a reef following disturbance (Wallace 1985, Harrison \& Wallace 1990, Soong et al. 2003). E. glabrescens is in the family Caryophylliidae, has large polyps, forms phaceloid colonies, and hosts zooxanthellae. T. aurea is in the family Dendrophylliidae, has large polyps, forms massive colonies, and does not host zooxanthellae. It typically aggregates in crevices and cryptic habitats. The results of this study showed that these brooding species possess variable strategies of reproductive timing. 


\section{MATERIALS AND METHODS}

Collection sites. Colonies of Seriatopora hystrix (6.7 to $27.0 \mathrm{~cm}$ in diameter) were from Leidashyr $\left(21^{\circ} 55^{\prime} 89^{\prime \prime} \mathrm{N}, 120^{\circ} 45^{\prime} 69^{\prime \prime} \mathrm{E}\right)$, colonies of Stylophora pistillata (10.0 to $26.0 \mathrm{~cm}$ in diameter) and Pocillopora damicornis (8.2 to $18.0 \mathrm{~cm}$ in diameter) were from Hobihu (21 $56^{\prime} 29^{\prime \prime} \mathrm{N}, 120^{\circ} 44^{\prime} 70^{\prime \prime} \mathrm{E}$ ), while those of Euphyllia glabrescens ( 7.2 to $35.8 \mathrm{~cm}$ in diameter) and Tubastraea aurea (6.7 to $20.3 \mathrm{~cm}$ in diameter) were from the inlet of a power plant $\left(21^{\circ} 57^{\prime} 37^{\prime \prime} \mathrm{N}\right.$, $120^{\circ} 45^{\prime} 29^{\prime \prime} \mathrm{E}$ ). All colonies were collected at depths of 3 to $8 \mathrm{~m}$ on fringing reefs in southern Taiwan (Fig. 1). The distances among the 3 sites was 1 to $3 \mathrm{~km}$.

Planula collection. Intact or partial colonies were removed from the reef using a hammer and chisel. Colonies were transported within $1 \mathrm{~h}$ to the husbandry center of the National Museum of Marine Biology and Aquarium. Each colony was placed in a separate tank

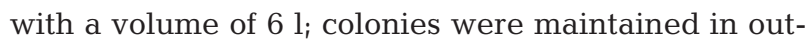
door flow-through seawater systems with running seawater at a rate of approximately $11 \mathrm{~min}^{-1}$ under a natural photoperiod and at ambient temperatures (but the temperature was not allowed to exceed $28^{\circ} \mathrm{C}$, which was controlled by a chiller and an automated microcomputer) (Fan et al. 2002). Seawater was pumped from inshore (at a depth of $5 \mathrm{~m}$ ) and was run through sand filters $(50 \mu \mathrm{m})$. Colonies were replaced monthly with newly-collected samples at the end of the lunar month so that they might more closely represent planulation activity in the field. The outflow of each tank was passed through a collecting cup with a sieve made from a plankton net (mesh size $100 \mu \mathrm{m}$ ) to trap the released planulae. The mesh size was appropriate because the mean diameter of planulae for the 5 studied species range from 500 to $1500 \mu \mathrm{m}$ (Fan et al. 2002, authors' unpubl. data). The study was conducted in winter (February and March) and summer (July and August) 2003 with the total number of days of observation ranging from $7 \mathrm{~d}$ for Stylophora pistillata to $18 \mathrm{~d}$ for Tubastraea aurea (Figs. 2 to 6). For the 5 studied species, 8 colonies were observed during the monitoring period with the following exceptions: 16 colonies of Seriatopora hystrix were monitored from 1 to 7 July 2003 and 16 of Tubastraea aurea on 15, 16 and 23 March 2003. The number of planulae released by each colony was counted every hour.

Data analysis. To determine the diel periodicity of planula release, data from different days were pooled for analysis. Data at both the planula and colony levels were analyzed according to hour. Planula release time relative to the diel cycle $(24 \mathrm{~h})$ was expressed in degrees as an angle between 0 and $360^{\circ}$. Circular statistics were used to calculate mean angle (central tendency) and angular deviation (a measure of dispersion) for the diel periodicities (Zar 1999). Rayleigh tests were used to examine the null hypothesis that planulae were uniformly released throughout the day (Zar 1999). If the null hypothesis was rejected, the mean hour of planulation was calculated using circular statistics to determine the time that planulation was predominant.

\section{RESULTS}

The diel cycles of planulation of Seriatopora hystrix (Figs. 2, 7A \& 8A) and Stylophora pistillata (Figs. 3, 7B $\& 8 \mathrm{~B})$ were highly consistent among different dates and were synchronized with 1 high peak occurring close to sunrise. Sunrise occurred between 06:00 and 06:30 h from February to March and between 05:15 and 05:45 h from July to August. The clustering of pooled data of planulation from both the number of

Table 1. Seriatopora hystrix, Stylophora pistillata, Pocillopora damicornis, Euphyllia glabrescens, and Tubastraea aurea. Test for uniformity of diel distribution of planulation. Z: test statistic (Rayleigh's test), n: (A) no. of planulae released and (B) sum of observations of colonies releasing planulae at each hour, $^{*}: \mathrm{p}<0.001$, ns: not significant

\begin{tabular}{|c|c|c|c|c|c|}
\hline & S. hystrix & S. pistillata & P. damicornis & E. glabrescens & T. aurea \\
\hline \multicolumn{6}{|l|}{ (A) Planulae released } \\
\hline Mean hour & 4.9 & 6.1 & 3.2 & 23.4 & 4.6 \\
\hline Angular deviation & 21.3 & 29.4 & 46.9 & 66.3 & 79.8 \\
\hline$Z$ & 40150.5 & 570.8 & 9174.9 & 531.8 & 8.5 \\
\hline $\mathrm{n}$ & 46330 & 757 & 20768 & 4905 & 9436 \\
\hline Probability of uniform distribution & * & $*$ & * & * & $*$ \\
\hline \multicolumn{6}{|l|}{ (B) Colonies releasing planulae } \\
\hline Mean hour & 5.5 & 6.4 & 2.9 & 1.1 & 9.6 \\
\hline Angular deviation & 50.4 & 53.3 & 70.0 & 68.5 & 80.2 \\
\hline$Z$ & 337.3 & 53.1 & 86.2 & 34.8 & 0.5 \\
\hline $\mathrm{n}$ & 900 & 166 & 1357 & 431 & 1372 \\
\hline Probability of uniform distribution & * & $*$ & * & * & ns \\
\hline
\end{tabular}



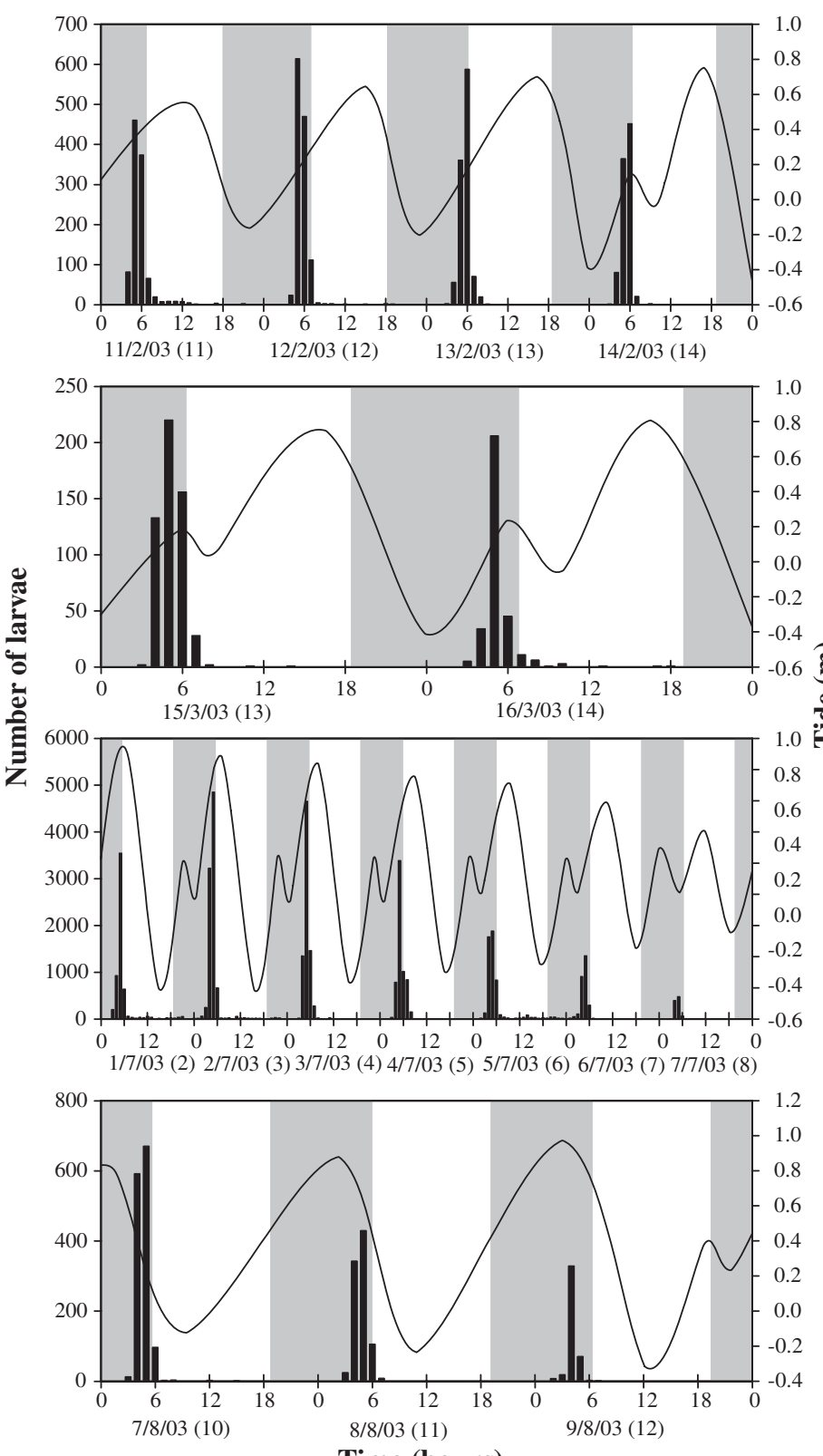

Time (hours)

Fig. 2. Seriatopora hystrix. No. of larvae collected during $24 \mathrm{~h}$ cycles on each monitoring day. Dates given as d/mo/yr (lunar day). Shaded area represents nighttime. Amplitude of tides is shown. Note different scales on the $y$-axes

planulae released and the number of colonies releasing planulae was significant ( $\mathrm{p}<0.001$, Table 1). For $S$. hystrix, the greatest proportion of colonies releasing planulae $(54.5 \%$, Fig. $8 \mathrm{~A})$ and the period of greatest planula release $(91.8 \%$ of planulae, Fig. $7 \mathrm{~A})$ occurred between 04:00 and 06:00 $\mathrm{h}$. The mean hour of planulation was 4.9 for planula release and 5.5 for planulating colonies (Table 1). For S. pistillata, the greatest proportion of colonies releasing planulae $(51.5 \%$, Fig. 8 B) and the period of greatest planulae release $(78.7 \%$ of plan-
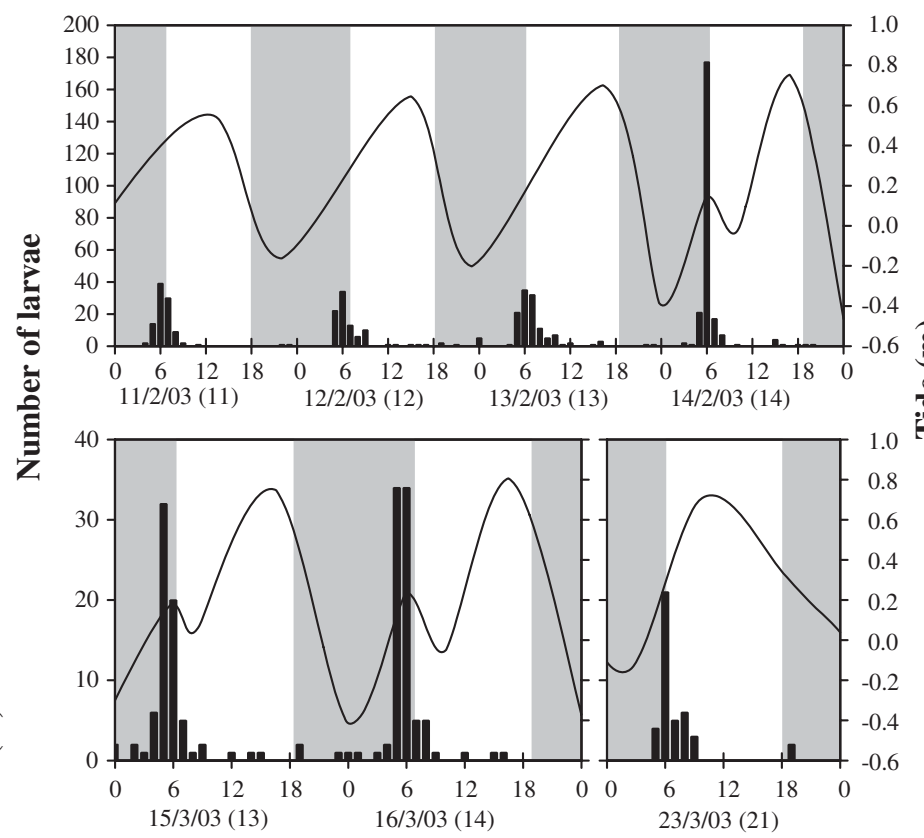

Time (hours)

Fig. 3. Stylophora pistillata. No. of larvae collected during $24 \mathrm{~h}$ cycles on each monitoring day. Dates given as $\mathrm{d} / \mathrm{mo} / \mathrm{yr}$ (lunar day). Shaded area represents nighttime. Amplitude of tides is shown. Note different scales on the $y$-axes

ulae, Fig. 7B) occurred between 05:00 and 07:00 h. The mean hour of planulation was 6.1 for the planulae released and 6.4 for the planulating colonies (Table 1).

Planulae of Pocillopora damicornis (Figs. 4, 7C \& 8C) were released throughout the day with 1 major peak occurring in the early morning. In addition, a second minor peak usually occurred in the evening in February and July. The single peak that occurred at noon on 11 February was influenced by 2 of 8 colonies and may be considered an artifact. Euphyllia glabrescens released planulae throughout the day and usually had 2 peaks that occurred in the early morning and in the evening, respectively (Figs. 5, 7D \& 8D). The peaks that occurred in the daytime on 2 and 5 July were influenced by 1 of 8 colonies and may be considered an artifact. Sunset occurred between 17:45 and 18:15 h from February to March and between 18:15 and 18:45 h from July to August.

The distribution of pooled data of planulation for both the number of planulae released and the colonies releasing planulae was significantly non-uniform $(\mathrm{p}<$ 0.001 , Table 1$)$. The majority of planulae $(56.9 \%)$ of Pocillopora damicornis were released between 02:00 and 05:00 h (Fig. $7 \mathrm{C}$ ). In addition, 2 peaks in the proportions of planulating colonies occurred between 00:00 and $06: 00 \mathrm{~h}(5.0$ to $8.0 \%)$ and at $20: 00 \mathrm{~h}(5.2 \%)$, respectively (Fig. 8C). For Euphyllia glabrescens, the distribution of planulation was dispersed with 2 

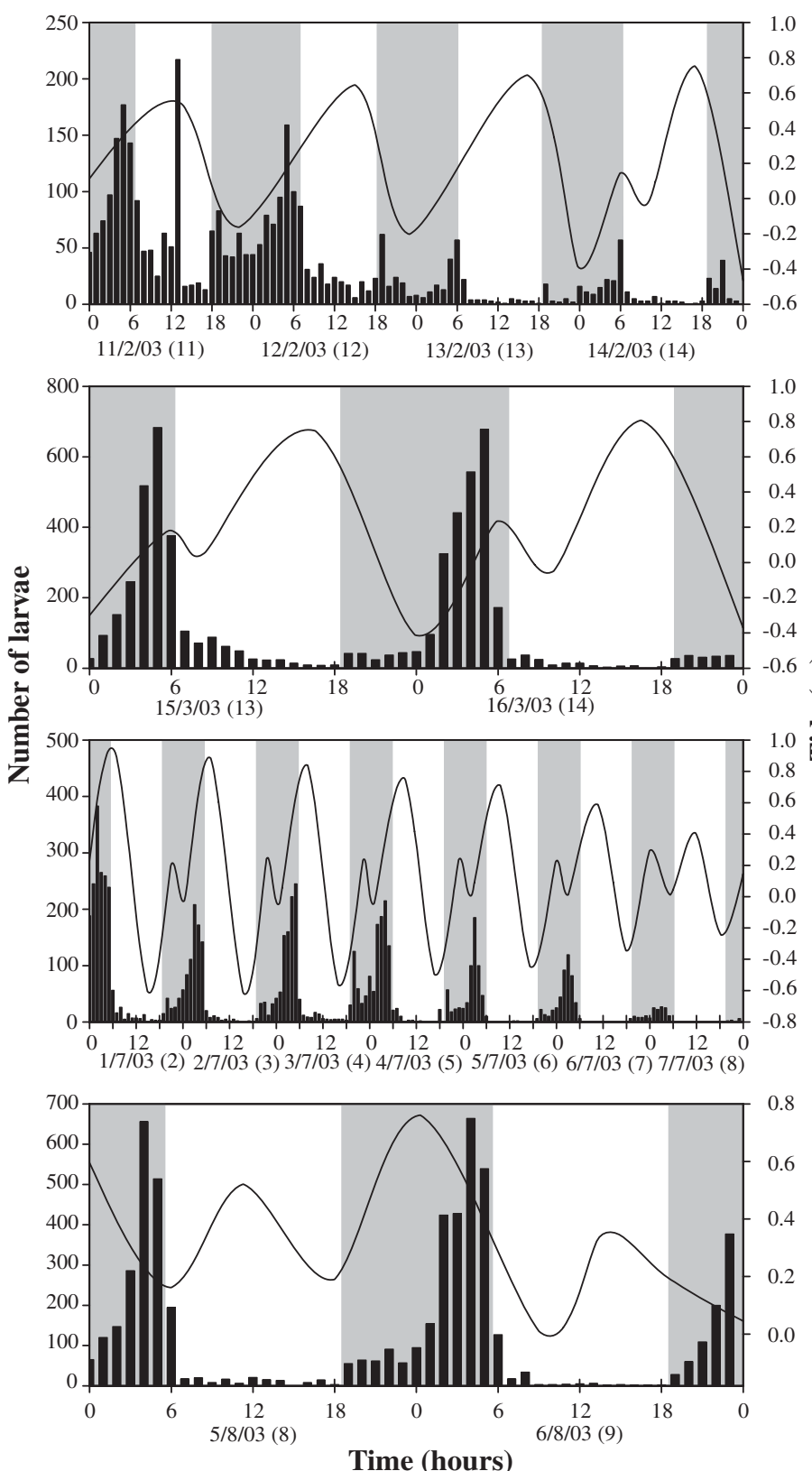

Fig. 4. Pocillopora damicornis. No. of larvae collected during $24 \mathrm{~h}$ cycles on each monitoring day. Dates given as d/mo/yr (lunar day). Shaded area represents nighttime. Amplitude of tides is shown. Note different scales on the $y$-axes

comparable low peaks in planula release occurring at 03:00 $\mathrm{h}$ and between 20:00 and 21:00 h (9.2 and 10.4 to $12.2 \%$, Fig. 7D); peaks in proportions of colonies releasing planulae occurred at 04:00 and 21:00 h (7.2 and $8.6 \%$, Fig. 8D), respectively.

Planulation of the ahermatypic coral Tubastraea aurea occurred throughout the day with no consistent diel periodicity among different dates (Fig. 6). The distribution of the number of planulae released was nonuniform ( $p<0.001$, Table 1, Fig. 7E), but the propor-
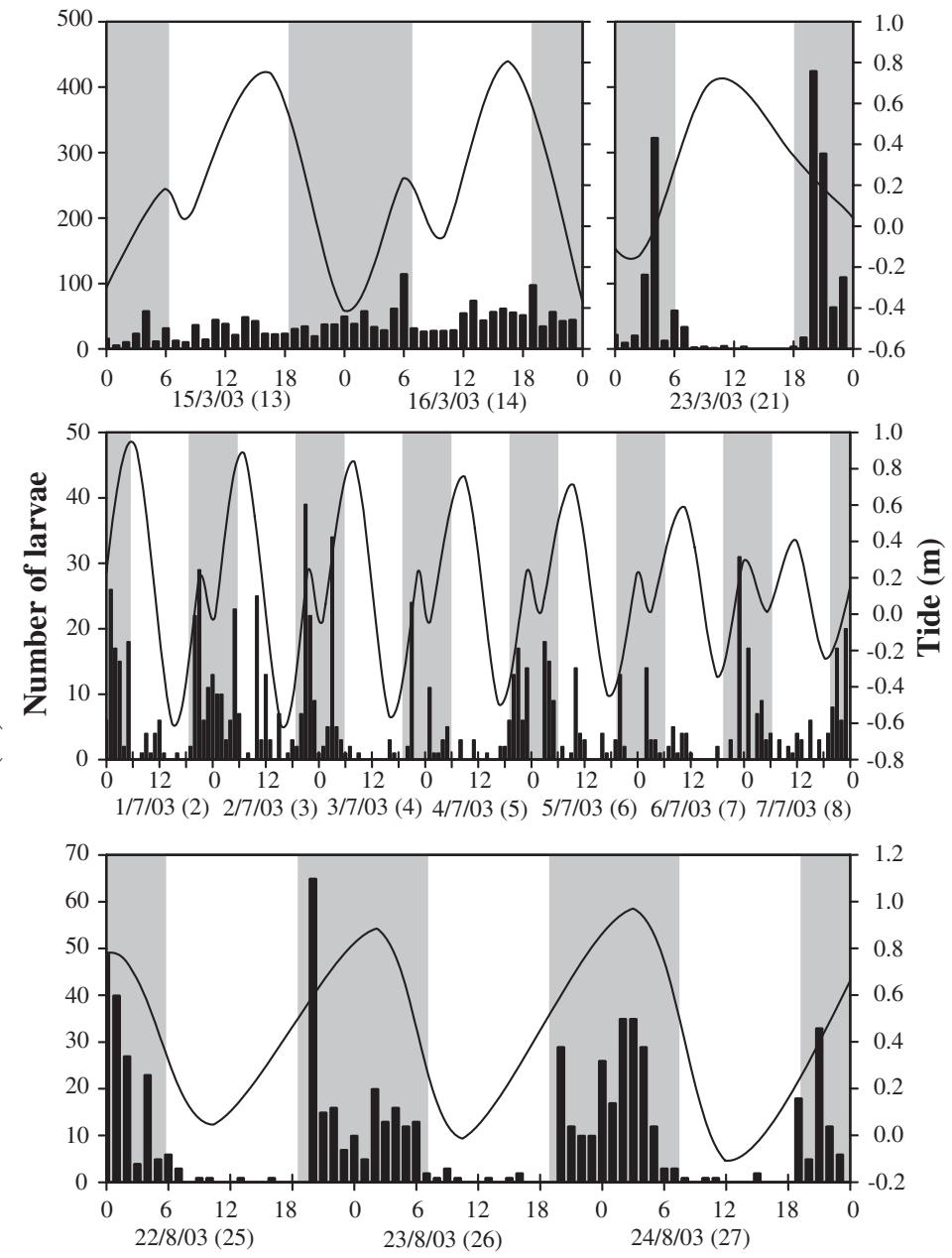

Time (hours)

Fig. 5. Euphyllia glabrescens. No. of larvae collected during $24 \mathrm{~h}$ cycles on each monitoring day. Dates given as $\mathrm{d} / \mathrm{mo} / \mathrm{yr}$ (lunar day). Shaded area represents nighttime. Amplitude of tides is shown. Note different scales on the $y$-axes

tions of released planulae during the daytime (48.9\%) and nighttime $(51.1 \%)$ were similar. The distribution of the percentage of planulating colonies was uniform (Table 1, Fig. 8E).

The angular deviations (21.3 to 46.9) of planulae released by Seriatopora hystrix, Stylophora pistillata, and Pocillopora damicornis were lower than those (50.4 to 70.0) of colonies releasing planulae (Table 1). This indicates that the synchrony of planula release was higher than that of planulating colonies. However, the angular deviations of planulae released and colonies releasing planulae of Euphyllia glabrescens and Tubastraea aurea were similar.

The angular deviations (21.3 and 29.4 for planulae released, 50.4 and 53.3 for planulating colonies) of planulation in Seriatopora hystrix and Stylophora pistillata were lower than those (46.9 to 79.8 for the number of planulae released and 68.5 to 80.2 for plan- 

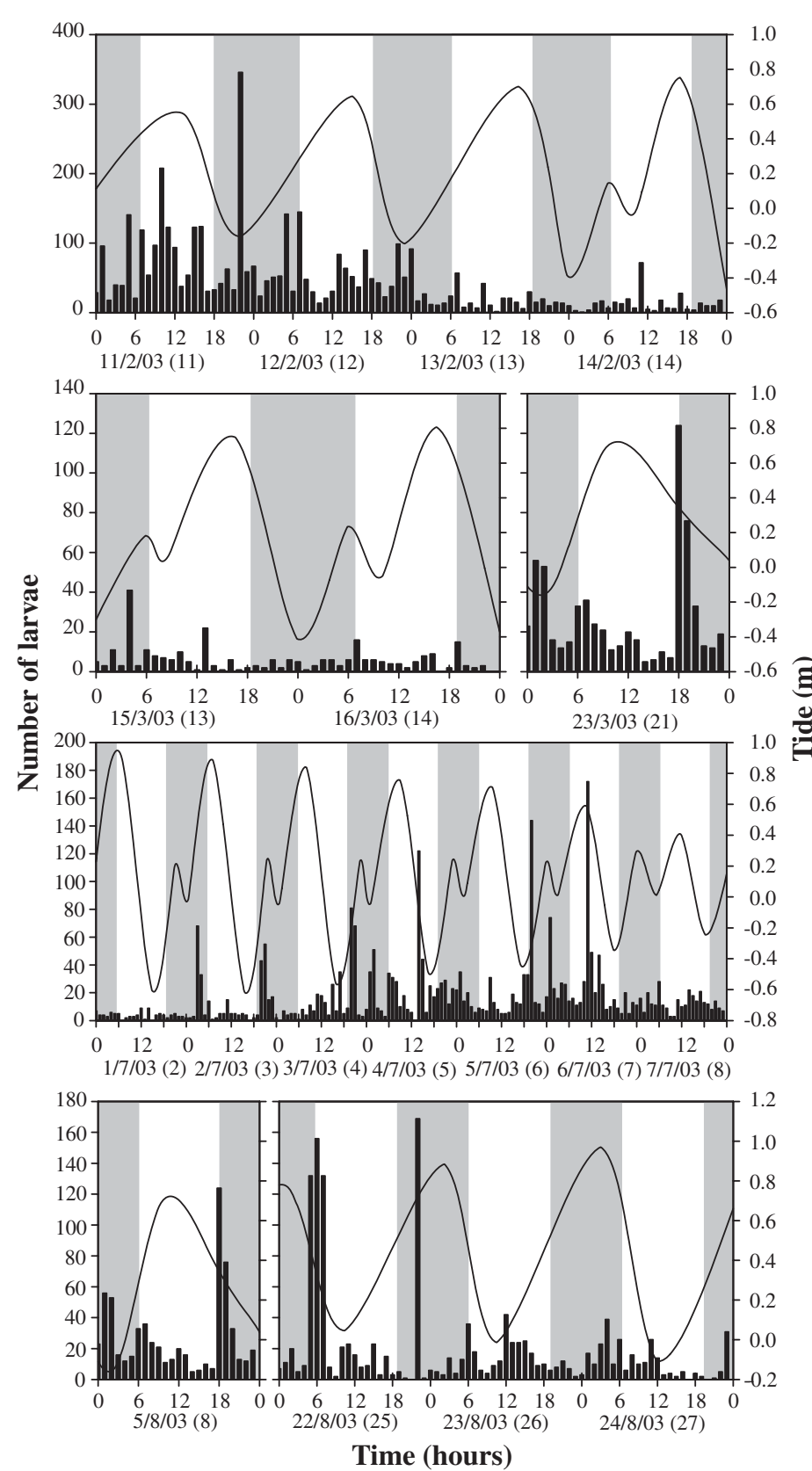

Fig. 6. Tubastraea aurea. Number of larvae collected during $24 \mathrm{~h}$ cycles on each monitoring day. Dates given as $\mathrm{d} / \mathrm{mo} / \mathrm{yr}$ (lunar day). Shaded area represents nighttime. Amplitude of tides is shown. Note different scales on the $y$-axes

ulating colonies) in Pocillopora damicornis, Euphyllia glabrescens, and Tubastraea aurea (Table 1). This indicates that the diel periodicity of planulation in $S$. hystrix and $S$. pistillata was more synchronous among the 5 brooding coral species.

Diel patterns of planula release for the 5 studied species were independent of the tidal cycle because they showed no temporal relationship to the tidal phase (Figs. 2 to 6).

\section{DISCUSSION}

Several methods, including collection of planulae released in the field, observation of planulae released from corals kept in aquaria or outdoor flow-through systems, as well as examination of planulae inside polyps of fragments collected from the field, have been used to determine the timing of larval release by corals (Richmond \& Jokiel 1984, Jokiel 1985, Tanner 1996, Fan et al. 2002, Vermeij et al. 2003). The periodicity of planulation studied using flow-through aquarium systems in the laboratory can be examined more intensively, and results are comparable to planula collections from field studies, as reported in other studies (Richmond \& Jokiel 1984, Jokiel 1985, Tanner 1996, Fan et al. 2002).

The diel periodicity of planula release of all 3 pocilloporids and Euphyllia glabrescens suggests that the light-dark cycle may play an important role in controlling the rhythm. Experimental manipulation of the daily light and dark cycles indicated that the photoperiod controls the final synchronization and timing of reproduction in some corals (Harrison \& Wallace 1990). Different timing of planula release between species may have resulted from differential responses to the light-dark cycle as suggested for the different spawning times of broadcasting coral species (Fukami et al. 2003).

The timing of reproduction may reflect environmental conditions favorable for the survival of larvae (Giese \& Pearse 1974). There were peaks in planulation of all 3 pocilloporids and Euphyllia glabrescens that occurred in the dark period. Planula release also predominantly occurred at night in Stylophora pistillata in the northern Gulf of Eilat, Red Sea (Rinkevich \& Loya 1979a), in Pocillopora damicornis from the Great Barrier Reef (Harriott 1983), in Acropora cuneata on Heron Island reef, Great Barrier Reef (Kojis 1986), in Favia fragum in Puerto Rico (Szmant-Froelich et al. 1985), in Agaricia humilis from the Netherlands Antilles (Morse \& Morse 1991), in Manicina areolata from Panama (Johnson 1992), and in Porites astreoides from Florida (McGuire 1998, Edmunds et al. 2001). Larvae released under the cover of darkness might be more likely to survive because corals produce visually conspicuous and weakly-swimming planulae that are vulnerable to planktivorous fishes (Babcock et al. 1986, Harrison \& Wallace 1990).

All 3 pocilloporids released more planulae in the early morning. Furthermore, planulation of Seriatopora hystrix and Stylophora pistillata was highly synchronized into a single peak of planula release that occurred near sunrise. It was reported that planulae of S. hystrix, S. pistillata, and Pocillopora damicornis from Okinawa were released only in the early morning 

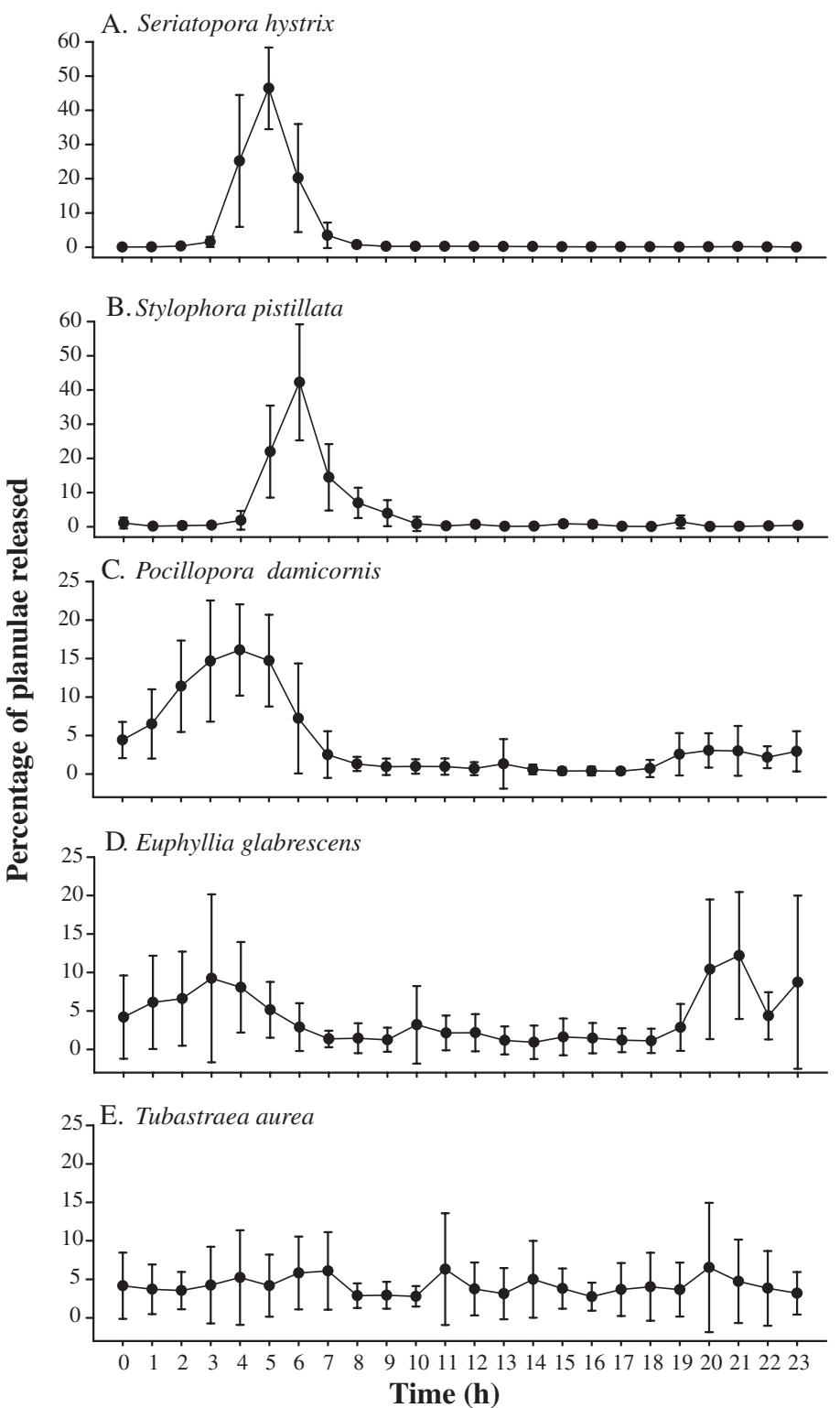

Fig. 7. Seriatopora hystrix, Stylophora pistillata, Pocillopora damicornis, Euphyllia glabrescens, and Tubastraea aurea. Percentage of planulae released each hour. Data from all days were summed (mean $\pm \mathrm{SD}$ )

(Isomura \& Nishihira 2001, Nishikawa et al. 2003). Brooded planulae are usually released at an advanced stage of development and are capable of rapid settlement (Harrison \& Wallace 1990). In addition, coral planulae usually show light-dependent behavior and settle on preferable positions (Kawaguti 1941, Harrison \& Wallace 1990, Babcock \& Mundy 1996, Mundy \& Babcock 1998). It was reported that some planulae of the 3 pocilloporid corals began to settle within minutes to hours after release, and that they preferred to settle on cryptic sites (Harrison \& Wallace 1990, Isomura \& Nishihira 2001). Perhaps the advantage of peak
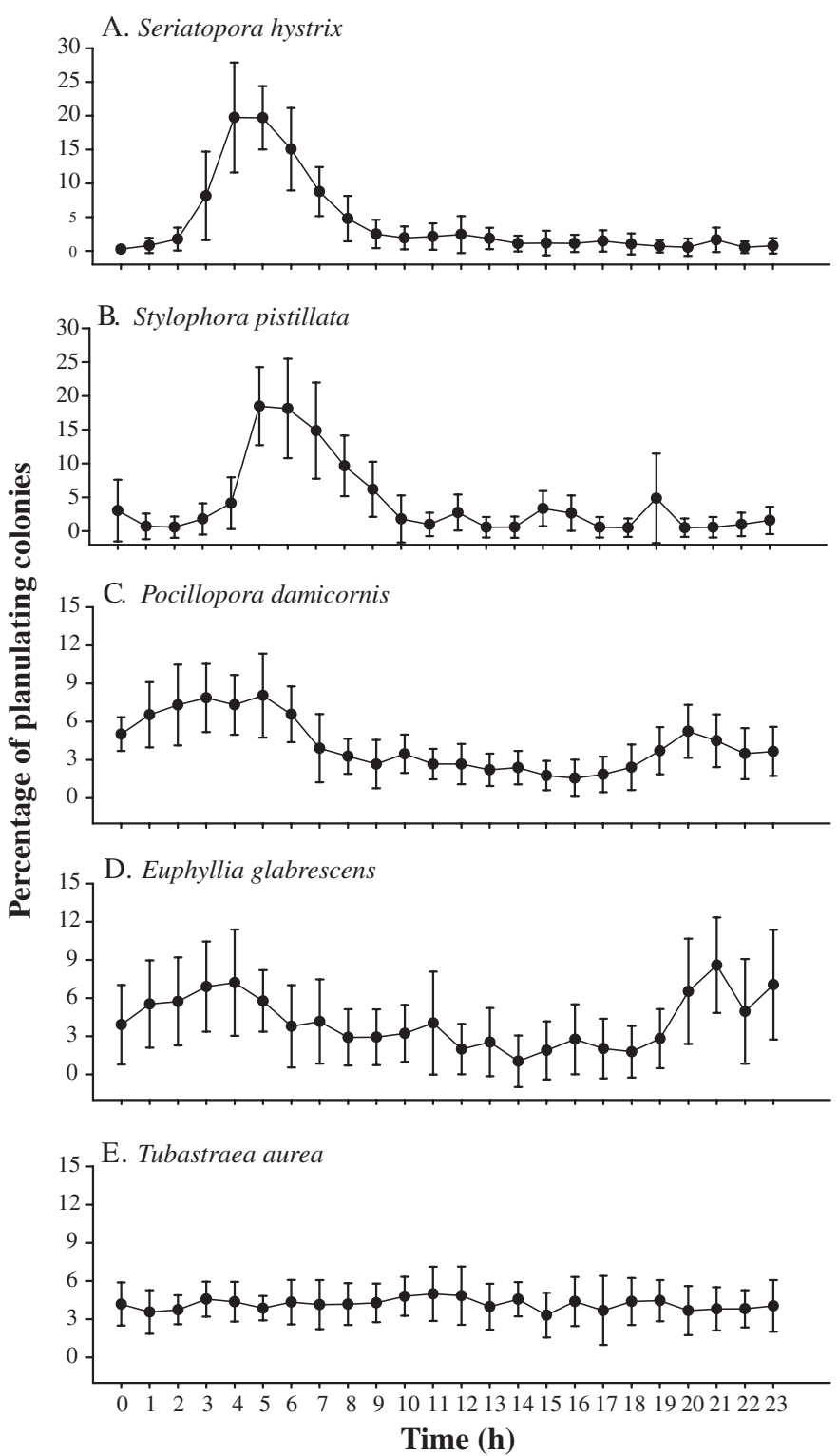

Fig. 8. Seriatopora hystrix, Stylophora pistillata, Pocillopora damicornis, Euphyllia glabrescens, and Tubastraea aurea. Percentage of planulating colonies each hour. Data from all days were summed (mean $\pm \mathrm{SD}$ )

release of planulae close to sunrise is the ability to use light cues after sunrise for settlement, thus shortening the duration in which they remain in the water column (Olson 1983). Therefore, a combination of light cues for settlement and avoidance of visual predators is more likely to be the selective agent for this converging timing pattern of planula release.

Furthermore, many planulae being released close to sunrise could result in newly-released mature planulae settling and being retained within the natal reef. The facilitation of self-recruitment might increase the survival rate by ensuring that planulae have a compatible 
environment, and may be regarded as an adaptive strategy (Mundy \& Babcock 1998, Isomura \& Nishihira 2001, Strathmann et al. 2002). The speculation that planulae are retained on the natal reef is supported by the fact that the 3 pocilloporids are abundant in the collection area and that they are the dominant recruits in southern Taiwan (Dai 1989, Soong et al. 2003). Several genetic studies have demonstrated highlyrestricted dispersal of larvae and local recruitment for brooding pocilloporid coral species (Ayre et al. 1997, Ayre \& Hughes 2000, Nishikawa et al. 2003).

On the other hand, some planulae can still retain a planktonic life for long-distance dispersal. It has been reported that newly-released planulae of the 3 pocilloporid corals showed great variations in size and lifetime, and thus dispersal potential (Isomura \& Nishihira 2001). In addition, larvae of Seriatopora hystrix and Stylophora pistillata released on different days had different settlement rates within $24 \mathrm{~h}$ (Fan et al. 2002). Szmant-Froelich et al. (1985) found that during the first few days of each planulation cycle of Favia fragum, most of the night-released planulae were found to be swimming the following morning, while toward the end of the cycle most of the planulae had already become loosely attached by the next morning. Edmunds et al. (2001) reported that planulae of the reef coral Porites astreoides differed physiologically among release dates. Therefore, corals may achieve both self-seeding and long-distance dispersal by releasing planulae at different developmental stages or at different times.

Geographic variations in the diel cycle of planula release occurs among allopatric populations of the same species (Harrison \& Wallace 1990). Larval release of all 3 pocilloporids and Euphyllia glabrescens in southern Taiwan coincided with the light-dark cycle, but was independent of the tidal cycle. Under laboratory conditions in southern Taiwan, Pocillopora damicornis released planulae throughout the day, with a single major peak that occurred in the early morning but that was independent of the tidal phase. However, for P. damicornis from Okinawa, Japan, planulation occurred only in the early morning under laboratory conditions (Isomura \& Nishihira 2001). Under laboratory conditions, planulation by $P$. damicornis from Amakusa, Japan, occurred from early to late morning and usually correlated with the low tide (Tioho et al. 2001). In the laboratory, $P$. damicornis from Hawaii showed a single peak in daily production of planulae (Holloran \& Witteman 1985). This peak occurred during periods of low tide and appeared to be independent of photoperiod. Planula release occurred only at night for $P$. damicornis at Lizard Island, Great Barrier Reef, under laboratory conditions (Harriott 1983). In addition, planulation of Stylophora pistillata in south- ern Taiwan under laboratory conditions mainly occurred close to sunrise, whereas $S$. pistillata in the field at Eilat, Red Sea, released more planulae after sunset and at night (Rinkevich \& Loya 1979a). Geographic variations in the timing of planula release may reflect local adaptations to environmental conditions so as to optimize planula survival and transportation (Richmond \& Jokiel 1984, Harrison \& Wallace 1990).

The 3 pocilloporid species in southern Taiwan showed some differences in reproductive traits. For example, the time of peak planulation differed by 1 to $3 \mathrm{~h}$ (Table 1). The diel periodicities of planulation by Seriatopora hystrix and Stylophora pistillata were more synchronous than that of Pocillopora damicornis (Table 1). The lunar periodicities of larval release of $S$. hystrix and P. damicornis were similar, but differed from that of S. pistillata (Fan et al. 2002, authors' unpubl. data). They also differed in planula size (Fan et al. 2002). The differentiation of reproductive traits may be advantageous to the coexistence of these sympatric species (Shlesinger \& Loya 1985).

Unlike the 4 studied hermatypic brooding species, the ahermatypic coral Tubastraea aurea released planulae throughout the day with no apparent differences between day and night. The planulae of $T$. aurea were large (ca. $900 \mu \mathrm{m}$ in diameter) and bright orange in color, and may be visually conspicuous to planktivorous fishes. Whether they possess some presentlyunidentified adaptation to reduce their vulnerability during daytime or capitalize on other advantages of all-day planulation remains unknown.

More studies quantifying larval release under laboratory and/or field conditions in other locations as well as rigorous experiments of possible causal factors of larval release and settlement are needed to better understand the geographic variability of larval release patterns and the mechanisms of locally adapted reproductive patterns.

Acknowledgements. We thank Dr. M. L. Tsai and Mr. P. J. Liu for statistical assistance. We thank Dr. K. Soong and 3 anonymous reviewers for useful comments on an earlier draft of this manuscript. This study was supported by a grant from the National Science Council, ROC (NSC 92-2621-B-291-001).

\section{LITERATURE CITED}

Atoda K (1947a) The larva and postlarval development of some reef-building corals. I. Pocillopora damicornis cespitosa (Dana). Sci Rep Tohoku Univ 4 Ser 18:24-47

Atoda K (1947b) The larva and postlarval development of some reef-building corals. II. Stylophora pistillata (Esper). Sci Rep Tohoku Univ 4 Ser 18:48-64

Atoda K (1951) The larva and postlarval development of some reef-building corals. III. Seriatopora hystrix Dana. Sci Rep Tohoku Univ 4 Ser 19:33-39 
Ayre DJ, Hughes TP (2000) Genotypic diversity and gene flow in brooding and spawning corals along the Great Barrier Reef, Australia. Evolution 54:1590-1605

Ayre DJ, Hughes TP, Standish RJ (1997) Genetic differentiation, reproductive mode, and gene flow in the brooding coral Pocillopora damicornis along the Great Barrier Reef, Australia. Mar Ecol Prog Ser 159:175-187

Babcock R, Mundy C (1996) Coral recruitment: consequences of settlement choice for early growth and survivorship in two scleractinians. J Exp Mar Biol Ecol 206:179-201

Babcock RC, Bull GD, Harrison PL, Heyward AJ, Oliver JK, Wallace CC, Willis BL (1986) Synchronous spawnings of 105 scleractinian coral species on the Great Barrier Reef. Mar Biol 90:379-394

Babcock RC, Willis BL, Simpson CJ (1994) Mass spawning of corals on a high latitude coral reef. Coral Reefs 13:161-169

Dai CF (1989) Scleractinia of Taiwan. I. Families Astrocoeniidae and Pocilloporidae. Acta Oceanogr Taiwanica 22: 83-101

Edmunds PJ, Gates RD, Gleason DF (2001) The biology of larvae from the reef coral Porites astreoides, and their response to temperature disturbances. Mar Biol 139: 981-989

Fan TY, Li JJ, Ie SX, Fang LS (2002) Lunar periodicity of larval release by pocilloporid corals in southern Taiwan. Zool Stud 41:288-294

Fukami H, Omori M, Shimoike K, Hayashibara T, Hatta M (2003) Ecological and genetic aspects of reproductive isolation by different spawning times in Acropora corals. Mar Biol 142:679-684

Genin A, Jaffe JS, Reef R, Richter C, Franks PJS (2005) Swimming against the flow: a mechanism of zooplankton aggregation. Science 308:860-862

Giese AC, Pearse JS (1974) Introduction: general principles. In: Giese AC, Pearse JS (eds) Reproduction of marine invertebrates, Vol 1. Academic Press, New York, p 1-49

Hall VR, Hughes TP (1996) Reproductive strategies of modular organisms: comparative studies of reef-building corals. Ecology 77:950-963

Harriott VJ (1983) Reproductive seasonality, settlement, and post-settlement mortality of Pocillopora damicornis (Linnaeus), at Lizard Island, Great Barrier Reef. Coral Reefs 2: 151-157

Harrison PL, Wallace CC (1990) Reproduction, dispersal and recruitment of scleractinian corals. In: Dunbinsky Z (ed) Ecosystems of the world 25: Coral reefs. Elsevier, Amsterdam, p 133-207

Harrison PL, Babcock RC, Bull GD, Oliver JK, Wallace CC, Willis BL (1984) Mass spawning in tropical reef corals. Science 223:1186-1189

Holloran MK, Witteman GJ (1985) Diurnal periodicity in planula release by the reef coral Pocillopora damicornis. In: Jokiel PL, Richmond RH, Rogers RA (eds) Coral reef population biology. Hawaii Inst Mar Biol Tech Rep No. 37: 161-166

Isomura N, Nishihira M (2001) Size variation of planulae and its effect on the lifetime of planulae in three pocilloporid corals. Coral Reefs 20:309-315

Johnson KG (1992) Synchronous planulation of Manicina areolata (Scleractinia) with lunar periodicity. Mar Ecol Prog Ser 87:265-273

Jokiel PL (1985) Lunar periodicity of planula release in the reef coral Pocillopora damicornis in relation to various environmental factors. Proc 5th Int Coral Reef Symp 4: 307-312

Kawaguti S (1941) On the physiology of reef corals. V. Tropisms of coral planulae, considered as a factor of distribu- tion of the reefs. Palao Trop Biol Stat Stud 2:319-328

Kojis BL (1986) Sexual reproduction in Acropora (Isopora) species (Coelenterata: Scleractinia). I. A. cuneata and $A$. palifera on Heron Island Reef, Great Barrier Reef. Mar Biol 91:291-309

McGuire MP (1998) Timing of larval release by Porites astreoides in the northern Florida Keys. Coral Reefs 17: 369-375

Morgan SG (1995) The timing of larval release. In: McEdward L (ed) Ecology of marine invertebrate larvae. CRC Press, Boca Raton, FL, p 157-191

Morse DE, Morse ANC (1991) Enzymatic characterization of the morphogen recognized by Agaricia humilis (scleractinian coral) larvae. Biol Bull 181:104-122

Mundy CN, Babcock RC (1998) Role of light intensity and spectral quality in coral settlement: implications for depthdependent settlement? J Exp Mar Biol Ecol 223:235-255

Nishikawa A, Katoh M, Sakai K (2003) Larval settlement rates and gene flow of broadcast-spawning (Acropora tenuis) and planula-brooding (Stylophora pistillata) corals. Mar Ecol Prog Ser 256:87-97

Olson RR (1983) Ascidian-Prochloran symbiosis: the role of larval photoadaptations in midday larval release and settlement. Biol Bull 165:221-240

Richmond RH, Hunter CL (1990) Reproduction and recruitment of corals: comparisons among the Caribbean, the tropical Pacific, and the Red Sea. Mar Ecol Prog Ser 60: 185-203

Richmond RH, Jokiel PL (1984) Lunar periodicity in larva release in the reef coral Pocillopora damicornis at Enewetak and Hawaii. Bull Mar Sci 34:280-287

Rinkevich B, Loya Y (1979a) The reproduction of the Red Sea coral Stylophora pistillata. I. Gonads and planulae. Mar Ecol Prog Ser 1:133-144

Rinkevich B, Loya Y (1979b) The reproduction of the Red Sea coral Stylophora pistillata. II. Synchronisation in breeding and seasonality of planulae shedding. Mar Ecol Prog Ser $1: 145-152$

Shanks AL, Brink L (2005) Upwelling, downwelling, and cross-shelf transport of bivalve larvae: test of a hypothesis. Mar Ecol Prog Ser 302:1-12

Shlesinger Y, Loya Y (1985) Coral community reproductive patterns: Red Sea versus the Great Barrier Reef. Science 228:1333-1335

Soong K, Chen MH, Chen CL, Dai CF, Fan TY, Li JJ, Fan HM (2003) Spatial and temporal variation of coral recruitment in Taiwan. Coral Reefs 22:224-228

Stimson JS (1978) Mode and timing of reproduction in some common hermatypic corals of Hawaii and Enewetak. Mar Biol 48:173-184

Stoddart JA, Black R (1985) Cycles of gametogenesis and planulation in the coral Pocillopora damicornis. Mar Ecol Prog Ser 23:153-164

Strathmann RR, Hughes TP, Kuris AM, Lindeman KC, Morgan SG, Pandolfi JM, Warner RR (2002) Evolution of local recruitment and its consequences for marine populations. Bull Mar Sci 70:377-396

Szmant-Froelich AM, Reutter M, Riggs L (1985) Sexual reproduction of Favia fragum (Esper): lunar patterns of gametogenesis, embryogenesis and planulation in Puerto Rico. Bull Mar Sci 37:880-892

Tanner JE (1996) Seasonality and lunar periodicity in the reproduction of pocilloporid corals. Coral Reefs 15:59-66

Tioho H, Tokeshi M, Nojima S (2001) Experimental analysis of recruitment in a scleractinian coral at high latitude. Mar Ecol Prog Ser 213:79-86

Underwood AJ, Fairweather PG (1989) Supply-side ecology 
and benthic marine assemblages. Trends Ecol Evol 4: $16-20$

Vermeij MJA, Sampayo E, Broker K, Bak RPM (2003) Variation in planulae release of closely related coral species. Mar Ecol Prog Ser 247:75-84

Veron JEN (2000) Corals of the world, Vol 2. Australian Insti-

Editorial responsibility: Otto Kinne (Editor-in-Chief), Oldendorf/Luhe, Germany tute of Marine Science, Townsville

Wallace CC (1985) Seasonal peaks and annual fluctuations in recruitment of juvenile scleractinian corals. Mar Ecol Prog Ser 21:289-298

Zar JH (1999) Biostatistical analysis. Prentice-Hall, Englewood Cliffs, NJ

Submitted: May 13, 2005; Accepted: February 9, 2006

Proofs received from author(s): August 10, 2006 